\title{
Atopik Astımlı Türkiye Cumhuriyeti Vatandaşları ile Mültecilerin Deri Prick Test Sonuçlarının Karşılaştırılması
}

\section{The Comparison of Skin Prick Test Results of the Refugees with the Citizens of the Republic of Turkey with Atopic Asthma}

\author{
Serif KURTULUS ${ }^{1}{ }^{(D)}$, Remziye CAN ${ }^{2}(\mathbb{D})$, Zafer Hasan Ali SAK ${ }^{1}(\mathbb{C})$
}

1 Harran Üniversitesi Tıp Fakültesi, Göğüs Hastalıkları Anabilim Dalı, Şanlıurfa, Türkiye
2 Eskișehir Mustafa Kemal Atatürk Mesleki ve Teknik Anadolu Lisesi, Eskișehir, Türkiye

Öz.

Amaç: Bu çalışmanın amacı atopik astımlı Türkiye Cumhuriyeti (T.C.) vatandaşları ile Suriyeli mültecilerin Deri Prick Test (DPT) sonuçlarını değerlendirmektir.

Materyal ve Metod: Kesitsel tasarımlı bu çalışma 431 hasta ile Ocak 2015-2017 tarihleri arasında yürütülmüştür. Çalışmada atopik astımlı T.C. vatandaşları ile çadır kampta yaşayan ve atopik astımlı Suriyeli mültecilerin DPT sonuçları değerlendirildi. Bu çalışma için Harran Üniversitesi'nin girişimsel olmayan etik kurulundan 06.04.2017 tarih ve 17/04/23 sayılı karar ile izin alınmıştır.

Bulgular: Atopik astım tanılı olgulardan \%45,7'si Suriyeli mülteciler olmak üzere toplam 431 hastaya DPT yapıldı. Kadınlar olguların \%75,4'ünü oluşturuyordu. Ortalama yaş 30,5 idi. Hem T.C. vatandaşı hem de mültecilerde en çok görülen alerjen ev tozu akarı idi. Uyruğa göre: mantar karışımı $(p<0,001)$, hamam böceği $(p<0,05)$ ve tahıl karışımı $(p<0,05)$ açısından gruplar arasında anlamlı fark izlendi. Cinsiyete göre: mantar karışımı $(p<0,05)$ ve hamam böceğine $(p<0,05)$ karşı gruplar arasında anlamlı fark izlendi. T.C. vatandaşı kadınlarda yabani ot $(\% 41)$ ve kedi tüyü $(\% 39,1)$, Suriyeli mülteci kadınlarda mantar karışımı $(\% 61,9)$, Suriyeli mülteci erkeklerde yabani ot $(\% 60,7)$ duyarlıı̆ıının daha fazla olduğu izlendi.

Sonuç: Göç ve mültecilik durumlarında alerjik astım önemli bir sağlık sorunudur. T.C. vatandaşları ve mültecilerde en sık alerjen pozitifliği ev tozu akarında görülmektedir. Suriyeli mültecilerde sırayla ev tozu akarı, ot karışımı ve mantar karışımı şeklindedir. Bu çalışma mültecilerde alerjenleri gösteren ilk çalışma olmasıyla literatüre katkı sunacaktır.

Anahtar kelimeler: Alerjen, Astım, Deri Prick Test, Göçmen, Mülteci

Abstract

Background: The aim of this study to evaluate the results of the skin prick test (SPT) of citizens of the Republic of Turkey (T.R.) and Syrian refugees who are with atopic asthma.

Materials and Methods: This cross-sectional study was conducted with 431 patients between January 2015 and 2017. At the study were evaluated the results of the SPT of the citizens of the T.R with atopic asthma and Syrian refugees who are living in tent camps. For this study, approval was obtained from the non-interventional ethics committee of Harran University with the decision dated June 04, 2017 and numbered 17/04/23.

Results: SPT was performed in 431 patients with atopic asthma, $45.7 \%$ of whom were Syrian Refugees. Of the patients, $75.4 \%$ were female. The mean age was 30.5 . House dust mite is the most common allergen encountered in both Turkish citizens and refugees. By the nationality, a significant difference was observed between the groups in terms of mould mixture $(p<0.001)$, cockroach $(p<0.05)$ and grain mixture $(p<0.05)$. According to gender, there was a significant difference between the groups in terms of mould mixture $(p<0.05)$ and cockroach $(p<0.05)$. It was observed that the sensitivity of wild grass (41\%) and cat hair (39.1\%) in T.C women, mushroom mixture $(61.9 \%)$ in Syrian refugee women and wild grass $(60.7 \%)$ in Syrian refugee men were higher.

Conclusion: Allergic asthma is an important health problem in migration and refugee situations. In Turkish citizens and refugees, allergen positivity is most common in house dust mites. In Syrian refugees, it is as house dust mite, herb mix and mushroom mix, respectively. This study will contribute to the literature as it is the first study to show allergens in refugees.

Key words: Allergen, Asthma, Skin Prick Test, Immigrant, Refugee

\section{Sorumlu Yazar I Corresponding Author}

Dr. Şerif Kurtuluş

Harran Üniversitesi Tıp Fakültesi, Göğüs Hastalıkları Anabilim Dalı, Şanlıurfa, Türkiye

Te: +905052402773

e-mail: drkurtulus1@gmail.com

Geliş tarihi / Received:

09.05.2020

Kabul tarihi / Accepted: 07.07.2020

DOI: $10.35440 /$ hutfd. 734929

Bu makale 14-18 Ekim 2020 tarihleri arasında yapılacak olan Türk Toraks Derneği'nin 23. yıllık Kongresinde bildiri olarak kabul edilmiştir. 


\section{Giriş}

Astım kronik inflamasyon ve bronş aşırı duyarlıı̆̆ı ile seyreden değişken hava yolu obstrüksiyonu olarak tanımlanır $(1,2)$. Genetik, cinsiyet, obezite gibi kişiye ait ve sigara, mesleki maruziyetler, ev içi-ev dışı hava kirliliği ve enfeksiyonlar gibi çevreye ait faktörler astım gelişiminde rol oynar (2). Atopi ise genellikle çocukluk veya ergenlik döneminde, duyarlılaşmaya ve alerjenlere, genellikle proteinlere normal düzeyde maruz kalmaya yanıt olarak IgE antikorları üretmeye yönelik kişisel ve / veya ailesel bir eğilim olarak tanımlanır. Tip 1 hipersensitivite oluşturarak alerjik astım geliştirir (1-3). Atopik hastaların alerjenler nedeniyle yaklaşık yarısının solunum sistemi semptomları olduğu bildirilmiştir (3). Atopik kişilerde DPT ilk tercihtir. Minimal girişimsel bir işlem gerektirir. Genellikle güvenilirliği, güvenliği, rahatığı ve düşük maliyetli olması nedeniyle en yaygın kullanılan testtir $(4,5)$. Bu çalışmada atopik astımlı T.C. vatandaşları ile çadır kampta yaşayan Suriyeli mültecilerin DPT sonuçlarının değerlendirilmesi amaçlandı.

\section{Materyal ve Metod}

Kesitsel tasarımlı bu çalışma için Harran Üniversitesi girişimsel olmayan etik kuruldan 06.04.2017 tarihli ve 17/04/23 no'lu kararı ile izin alınmıştır. Ocak 2015 - Aralık 2017 tarihleri arasında Şanlıurfa Ceylanpınar Devlet Hastanesi Göğüs Hastalıkları Polikliniğine başvuran 234 T.C. vatandaşı ile 197 Suriyeli mülteci olmak üzere toplam 431 hasta çalışmaya alındı. Mülteciler şehir merkezine $13 \mathrm{~km}$ uzakta, sahrada (yaklaşık 5000 çadırdan oluşan ve 24000 kişinin yaşadığı, içinde hastanesi olan çadır kentte) ikamet etmekteydi. T.C. vatandaşları ise Suriye sınırında yer alan, ilçe merkezinde yaklaşık 44000 kişi olarak ikamet etmektedir (6). Her iki hastaneye başvuran ve Global Initiative for Astma (GINA)'ya göre Atopik Astım tanısı alan gönüllü hastalar çalışmaya dahil edildi. Hastaların kullandığı ilaçlar, ilaç türüne göre test yanlış negatifliğini önlemek için kesildi. DPT yapılırken onluk aplikatör ile spesifik alerjen solüsyonları ön kol ön yüzüne uygulandı. 15-20 dakika sonra test göğüs hastalıkları uzmanı tarafından değerlendirildi. Ödem; negatif kontrolden $3 \mathrm{~mm}$ daha büyükse, pozitif kabul edildi. Alerjen paneli olarak; mantar karışımı, ot karışımı, yabani ot, ağaç karışımı, tahıl karışımı, hamam böceği, kedi tüyü, ev tozu akarı, \%0,9 salin (negatif kontrol), ve histamin (pozitif kontrol) kullanıldı.

Verilerin analizi SPSS 21.0 istatistik paket programı (SPSS Inc., Chicago, Illinois, USA) kullanılarak yapılmıştır. Kolmogorov-Smirnov testi ile sürekli değişkenlerin dağıımının normal dağılıma uygun olup olmadıkları değerlendirilmiştir. Katılımcıların uyruk ve cinsiyet göre alerjen varlığı arasında fark olup olmadığı Ki-kare analizi ile karşılaştıııldı. Alerjen varlığının uyruk ve cinsiyete göre dağılımı Ki-kare analizi ile karşılaştıııldı. $p<0.05$ istatistiksel anlamlılık olarak kabul edilmiştir.

\section{Bulgular}

Bulgular: Çalışma grubunun 234'ü $(\% 54,3)$ T.C. Vatandaşı, 197'si (\%45,7) mültecilerden, 325'i $(\% 75,4)$ kadınlardan, 106'sı $(\% 24,6)$ erkeklerden oluşmuştur. Yaş grubu dağııımı 17-56 arasında, ortalama 30,55 \pm 10,13'tir (Tablo 1). Çalışma grubunun 316 'sının $(\% 73,3)$ ev tozu akarına, 235 'inin $(\% 54,5)$ ot karışımına, 153 'ünün $(\% 35,5)$ mantar karışımına, 152 'sinin $(\% 35,3)$ kedi tüyü, 152 'sinin $(\% 35,3)$ yabani ot, 150'sinin $(\% 34,8)$ tahıl karışımına, 127'sinin $(\% 29,5)$ ağaç karışımına, 64 'ünün $(\% 14,8)$ hamam böceğine alerjilerinin olduğu belirlenmiştir.

Tablo 1. Sosyo-Demografik Özelliklerin Dağılımı

\begin{tabular}{|c|c|c|c|}
\hline \multirow[t]{2}{*}{ Yaş } & \multirow[t]{2}{*}{ En düşük-en yüksek :17-56 } & \multicolumn{2}{|c|}{ Ortalama $=30,55 \pm 10.1$} \\
\hline & & $\mathrm{n}$ & $\%$ \\
\hline \multicolumn{4}{|c|}{ Cinsiyet } \\
\hline Kadır & & 325 & 75.4 \\
\hline Erkek & & 06 & 24.6 \\
\hline \multicolumn{4}{|c|}{ Uyruğu } \\
\hline Suriy & & 97 & 45.7 \\
\hline Türki & uriyeti Vatandaşı & 234 & 54.3 \\
\hline
\end{tabular}

Katılımcıların uyruklarına göre alerjen varlığı karşılaştıııldğında, T.C. vatandaşlarının 65 'inde $(\% 27,8)$, mültecilerin ise 88 'inde $(\% 44,7)$ mantar karışımı alerjisi olduğu, çaışma grubunun mantar karışımı alerjeni test pozitifliği ile bireylerin uyrukları arasında anlamlı fark olduğu tespit edilmiştir $(p<0,001)$. Çalışma gruplarındaki bireylerin uyruklarına göre test pozitifliği arasında fark tespit edilen alerjenlerden biri de tahıl karışımıdır. T.C vatandaşı katııımcılarda bu sıklık $94(\% 40,2)$ iken, mülteci katılımcılarında 56 $(\% 28,4)$ 'dır. Çalışma grubunun tahıl karışımı alerjeni test pozitifliği ile bireylerin uyrukları arasında anlamlı fark olduğu tespit edilmiştir $(p<0,05)$. T.C. vatandaşlarının 24'ü $(\% 10,3)$, mültecilerin ise 40 ' $(\% 20,3)$ hamam böceği alerjen pozitifliği göstermiştir. Çalışma grubunun hamam böceği alerjeni test pozitifliği ile bireylerin uyrukları arasında anlamlı fark olduğu tespit edilmiştir $(p<0,05)$. Çalışmamızda ot karışımı, yabani ot, ağaç karışımı, kedi tüyü, ev tozu akarı sıklığı açısından katılımcıların uyruğu arasında anlamlı bir fark saptanmamıştır (Tablo 2).

Çalışmamızda cinsiyete göre alerjen pozitifliği incelenmiştir. Erkeklerin 27 'sinin (\%25,5), kadınların ise 126'sının $(\% 38,8)$ mantar karışımı alerjenine karşı test pozitifliğinin olduğu saptanmıştır. Çalışma grubunun mantar karışımı alerjeni test pozitifliği ile cinsiyetleri arasında anlamlı fark olduğu tespit edilmiştir $(p<0,05)$. Çalışma grubundaki erkeklerin 9'unun $(\% 8,5)$, kadınların ise 55 'inin $(\% 16,9)$ hamam böceği alerjenine karşı test pozitifliğinin olduğu saptanmıştır. Çalışma grubunun hamam böceği alerjeni test pozitifliği ile cinsiyetleri arasında anlamlı fark olduğu tespit edilmiştir $(p<0,05)$. Çalışmamızda ot mix, yabani ot, ağaç mix, kedi tüyü, ev tozu akarı ile katılımcıların cinsiyet grupları arasında anlamlı bir fark saptanmamıştır (Tablo 3). 
Tablo 2. Çalışma Grubunun Uyruğuna Göre Alerjen Varlığı

\begin{tabular}{|c|c|c|c|c|}
\hline & $\begin{array}{l}\text { T.C. } \\
\text { vatandaşı } \\
\mathrm{n}(\%)\end{array}$ & $\begin{array}{l}\text { Mülteci } \\
\text { n(\%) }\end{array}$ & $\begin{array}{l}\text { Toplam } \\
\mathrm{n}(\%)\end{array}$ & $P$ \\
\hline $\begin{array}{l}\text { Mantar } \\
\text { Karısımı }\end{array}$ & $65(\% 27,8)$ & $88(\% 44,7)$ & $153(\% 35,5)$ & 0,000 \\
\hline $\begin{array}{l}\text { Ot } \\
\text { Karışımı }\end{array}$ & $130(\% 55,6)$ & $105(\% 53,3)$ & $235(\% 54,5)$ & 0,698 \\
\hline Yabani Ot & $88(\% 37,6)$ & $64(\% 32,5)$ & $152(\% 35,3)$ & 0,267 \\
\hline $\begin{array}{l}\text { Ağaç } \\
\text { karışımı }\end{array}$ & $72(\% 30,8)$ & $55(\% 27,9)$ & $127(\% 29,5)$ & 0,517 \\
\hline $\begin{array}{l}\text { Tahıl } \\
\text { Karışımı }\end{array}$ & $94(\% 40,2)$ & $56(\% 28,4)$ & $150(\% 34,8)$ & 0,011 \\
\hline $\begin{array}{l}\text { Hamam } \\
\text { Böceği }\end{array}$ & $24(\% 10,3)$ & $40(\% 20,3)$ & $64(\% 14,8)$ & 0,003 \\
\hline Kedi Tüyü & $89(\% 38,0)$ & $63(\% 32,0)$ & $152(\% 35,3)$ & 0,189 \\
\hline $\begin{array}{l}\text { Ev Tozu } \\
\text { Akarı }\end{array}$ & $167(\% 71,4)$ & $149(\% 75,6)$ & $316(\% 73,3)$ & 0,318 \\
\hline
\end{tabular}

Tablo 3. Çalışma Grubunun Cinsiyete Göre Alerjen Varlığı

\begin{tabular}{lllll}
\hline & Kadın & Erkek & Toplam & P \\
& $\mathrm{n}(\%)$ & $\mathrm{n}(\%)$ & $\mathrm{n}(\%)$ & \\
\hline Mantar Karısııııı & $126(\% 38,8)$ & $27(\% 25,5)$ & $153(\% 35,5)$ & $\mathbf{0 , 0 1 3}$ \\
Ot Karısıııı & $183(\% 56,3)$ & $52(\% 49,1)$ & $235(\% 54,5)$ & 0,194 \\
Yabani Ot & $111(\% 34,2)$ & $41(\% 38,7)$ & $152(\% 35,3)$ & 0,399 \\
Ağaç Karısıııı & $97(\% 29,8)$ & $30(\% 28,3)$ & $127(\% 29,5)$ & 0,762 \\
Tahıl Karısıımı & $110(\% 33,8)$ & $40(\% 37,7)$ & $150(\% 34,8)$ & 0,465 \\
Hamam Böceği & $55(\% 16,9)$ & $9(\% 8,5)$ & $64(\% 14,8)$ & 0,034 \\
Kedi Tüyü & $111(\% 34,5)$ & $41(\% 38,7)$ & $152(\% 35,3)$ & 0,466 \\
Ev Tozu Akarı & $233(\% 71,7)$ & $83(\% 78,3)$ & $316(\% 73,3)$ & 0,226 \\
\hline
\end{tabular}

Tablo 4. Alerjen varlığının uyruk ve cinsiyete göre dağııımı

\begin{tabular}{|c|c|c|c|c|}
\hline & \multicolumn{2}{|c|}{ Uyruk } & \multirow[b]{2}{*}{$\begin{array}{l}\text { Toplam } \\
\text { n(\%) }\end{array}$} & \multirow[b]{2}{*}{$P$ değeri } \\
\hline & $\begin{array}{l}\text { TC. } \\
\text { n(\%) }\end{array}$ & $\begin{array}{l}\text { Mülteci } \\
\text { n(\%) }\end{array}$ & & \\
\hline \multicolumn{5}{|l|}{$\begin{array}{l}\text { Mantar } \\
\text { karışımı }\end{array}$} \\
\hline Kadın & $48(38,1)$ & $78(61,9)$ & $126(38,8)$ & 0,003 \\
\hline Erkek & $17(21,8)$ & $10(35,7)$ & $27(25,5)$ & 0,117 \\
\hline \multicolumn{5}{|l|}{ Ot karışımı } \\
\hline Kadın & $89(48,6)$ & $94(51,4)$ & $183(56,3)$ & 0,441 \\
\hline Erkek & $41(8,8)$ & $11(21,2)$ & $52(49,1)$ & 0,162 \\
\hline \multicolumn{5}{|l|}{ Yabani ot } \\
\hline Kadın & $64(41,0)$ & $47(27,8)$ & $111(34,2)$ & 0,008 \\
\hline Erkek & $24(30,8)$ & $17(60,7)$ & $41(38,7)$ & 0,005 \\
\hline \multicolumn{5}{|l|}{$\begin{array}{l}\text { Ağaç } \\
\text { karışımı }\end{array}$} \\
\hline Kadın & $49(31,4)$ & $48(28,4)$ & $97(29,8)$ & 0,319 \\
\hline Erkek & $23(29,5)$ & $7(25,0)$ & $30(28,3)$ & 0,414 \\
\hline \multicolumn{5}{|l|}{ Kedi Tüyü } \\
\hline Kadın & $61(39,1)$ & $50(29,6)$ & $111(34,2)$ & 0,045 \\
\hline Erkek & $28(35,9)$ & $13(46,4)$ & $41(38,7)$ & 0,224 \\
\hline $\begin{array}{l}\text { Ev Tozu } \\
\text { Akarı }\end{array}$ & & & & \\
\hline Kadın & $106(67,9)$ & $127(75,1)$ & $233(71,7)$ & 0,094 \\
\hline Erkek & $61(78,2)$ & $22(78,6)$ & $83(78,3)$ & 0,598 \\
\hline
\end{tabular}

Suriyeli mülteci kadınların $\% 61,9^{\prime} u$ ile T.C. vatandaşı kadınların \%38,1'inin mantar karışımına alerjisi olduğu saptanmıştır. Suriyeli mülteci ve T.C. vatandaşı kadın cinsiyet ile mantar karışım duyarlıı̆̆ı arasında anlamlı fark olduğu saptanmıştır. Katılımcıların cinsiyetlerine göre yabani ot alerjen dağılımları incelendiğinde; T.C. vatandaşı kadınların \%41'inin, Suriyeli Mülteci kadınların \%27,8'nin yabani ota alerjisi olduğu, Suriyeli mülteci ve T.C. vatandaşı kadın cinsiyet ile yabani ot duyarılığı arasında anlamlı fark olduğu saptanmıştır. Yabani ot duyarlıığının erkek cinsiyet arasındaki dağılımı incelendiğinde Suriyeli Mülteci erkeklerin $\% 60,7$ 'sinin ve T.C. vatandaşı erkeklerin \%30,8'inin yabani ot duyarlıığının olduğu belirlenmiştir. Suriyeli mülteci ve T.C. vatandaşı erkek cinsiyet ile yabani ot duyarlılığ arasında anlamlı fark olduğu saptanmıştır. Katıımcıların cinsiyetlerine göre kedi tüyü alerjen dağılımları incelendiğinde; T.C. vatandaşı kadınların \%39,1'inin, Suriyeli Mülteci kadınların \%29,6'sının kedi tüyü alerjisi olduğu, Suriyeli mülteci ve T.C vatandaşı kadın cinsiyet ile kedi tüyü alerjen duyarlıığı arasında anlamlı fark olduğu saptanmıştır (Tablo 4).

\section{Tartışma}

Çalışmamızda atopik astım tanılı 197'si $(\% 45,7)$ Suriyeli mülteciler olmak üzere toplam 431 hastaya DPT yapıldı. Kadın cinsiyet 325 kişi $(\% 75,4)$ idi. Yaş grubu dağılımı 1756 yaş arasında değişmekte olup ortalama 30,55 $\pm 10,13^{\prime}$ tür. Hem T.C. vatandaşı hem de mültecilerde en çok görülen alerjen ev tozu akarıdır. Uyruğa göre mantar karışımı $(p<0,001)$, hamam böceği $(p<0,05)$ ve tahıl karışımı $(p<0,05)$ grupları arasında anlamlı fark izlendi. Cinsiyete göre bakıldığında mantar karışımı $(p<0,05)$ ve hamam böceği $(p<0,05)$ açısından anlamlı fark izlendi. Uyruğa göre cinsiyet grupları açısından T.C. vatandaşı kadınlarda yabani ot $(\% 41)$ ve kedi tüyü $(\% 39,1)$, Suriyeli mülteci kadınlarda mantar karışımı $(\% 61,9)$ Suriyeli mülteci erkeklerde yabani ot $(\% 60,7)$ duyarlıığının anlamlı düzeyde fazla olduğu izlendi.

Mültecilik ve göç modern zamanların hastalık ya da ölümle sonuçlanabilecek acil koşullarından biridir. Ortadoğu'da yerinden edilme kentsel bir fenomendir ve yerinden edilmiş insanlar kamplarda yaşarken çoğunluğu yoksul yerleşim alanlarında barınmaktadır $(7,8)$. Bu durum barınak eksikliği, yetersiz beslenme, yetersiz hijyen, dil-iletişim problemleri ve sağlık hizmetlerine yetersiz erişim gibi sağlık sorunlarının artmasını beraberinde getirmektedir. Bu durum aynı zamanda yaşam kalitesinin azalması ve bakım maliyetleri yönünden de önem arz eder. Çıtıl ve arkadaşlarının göçler ve enfeksiyon hastalıkları üzerine yazdıkları bir derlemede mültecilerde solunum yolu hastalıklarının sık görüldüğü ve altı ölümden birinden sorumlu olduğunu bildirmişlerdir (8, 9). Mültecilerin kaldığı kamp doğa ile iç içe, kentleşmeden uzak kendine has değişkenlerin olduğu bir yaşam alanı olması nedeniyle bu çalışma alerjen pozitifliği yönüyle literatüre katkı sunacaktır

Kanada'da Ahmed ve arkadaşları tarafından 623 astımlı hasta ile yapılan çalışmada kedi epiteli $(\% 53,1)$, ev tozu akarı $(\% 50,3)$ ve ot karışımına $(\% 39,2)(10)$ bağlı alerjilerin sık olduğu gözlendi. Çin'de yapılan bir çalışmada en sık ev 
tozu akarına (\%71,1), İran'da Farrokhi ve arkadaşları tarafından 176 hasta ile yapılan çalışmada en sık ev tozu akarına $(\% 90,5)(11)$ bağlı alerji bulunduğu bildirilmiştir. Ülkemizde Bayram ve arkadaşları 1627 hasta (en az bir alerjen pozitifliği gösteren 528 hasta) ile komşu şehir Gaziantep'te yaptıkları çalışmada en sık ot karışımına $(\% 41,8)$, ikinci sırada hamam böceğine $(\% 32,9)$, üçüncü sırada ev tozu akarına (\%32,7) (12), Koç ve arkadaşları 146 hasta ile aynı şehrin farkı ilçesinde yaptıkları çalışmada en sık hamam böceğine $(\% 56,8)$, ikinci sırada tahıl karışımına $(\% 53,3)$ üçüncü sırada ot karışımına $(\% 36,5)(13)$ alerji pozitifliği olduğunu bildirmişlerdir. Çalışmamızda ise en sık ev tozu akarına $(\% 73,3)$, ikinci sırada ot karışımına $(\% 54,5)$, üçüncü sırada ise mantar karışımına $(\% 35,5)$ alerji pozitifliği olduğu tespit edildi. Uyruğa göre, Suriyeli mültecilerde sırayla ev tozu akarı, ot karışımı ve mantar karışımına alerji pozitifliği söz konusu iken T.C. vatandaşlarında ilk üç sıralama ev tozu akarı, ot karışımı ve tahıl karışımı şeklindedir. İsveç (14), Kanada (15), Filistin (16) ve Türkiye'de (17), astımı olan göçmen ve mülteciler için yapılan yayınlarda dezavantajlı grup olarak tanımlama yapılmıştır. Nemli ortam, konut koşulları, hamam böceklerinin varlığı, kentsel yaşam, çevresel maruziyetler, sağlık eşitsizliği gibi etmenler göçmen ailelerde astım yönünden risk teşkil etmekte iken, göçmen ailelerin doğan çocuklarında erken maruziyet nedeniyle daha çok astım ve atopi görüldüğü bildirilmiştir. Kamplarda yaşayan mültecilerde kent merkezlerinden uzak olması nedeniyle daha az astım ve atopi görülmesi beklenirken özellikle çocuklarda daha fazla olduğu bildirilmiştir (16). Türkiye'de Suriye sınırında bulunan ve mültecilerin yaşadığı çadır kampta Kurtuluş ve arkadaşlarının yaptığı araştırmada Suriyeli mülteciler arasında astımın \%18,7 ile en sık görülen solunum yolu hastalığı olduğu bildirilmiştir (17). Çalışmamızda katıımcıların uyruklarına göre alerjen varlığı karşılaştııılığında, mantar karışımına $(p<0,001)$, tahıl karışımına $(p<0,05)$ ve hamam böceğine $(p<0,05)$ alerjen pozitifliği gösterilmiş ve gruplar arasında anlamlı fark olduğu tespit edilmiştir.

Yetişkinlerde mantar duyarlıı̆ı olması ciddi astım ile ilişkilidir. Çocuklarda bu durum daha şiddetli astım ile ilişkilidir (18). Hamam böceği genellikle sosyoekonomik düzeyi düşük topluluklarda görülür. Hamam böceği güçlü alerjenler üretir ve dışkısı lgE seviyesini yükseltir. Ev tozu akarı ile hamam böceği birlikteliği sıktır. Benzer şekilde Isı, nem ve sosyoekonomik düzey ile ilişkilidir (19). En önemli kaynağı dermatophagoides cinsi akarlarıdır. Aktif akarlar ortamda 6-11 gün canlı kalabilirler $(10,20)$. Çalışmamızda ev tozu akarı mültecilerde $\% 75,6$, T.C. vatandaşlarında $\% 71,4$ olmak üzere toplamda $\% 73,3$ ve hamam böceği ise mültecilerde $\% 20,3$, T.C. vatandaşlarında $\% 10,3$ olmak üzere toplamda \%14,8 alerjen pozitifliği bulunmuştur.

İsveç'te yapılan bir çalışmada atopik astımlı göçmenler ile yerli halk arasında cinsiyet yönünden fark bulunmadığı bildirilmiştir (21). Kanada'da yapılan başka bir çalışmada ise cinsiyet ile alerjen pozitifliği karşılaştırılı̆̆ında anlamlı fark yoktu (10). Koç ve arkadaşları tahıl karışımına karşı kadın cinsiyet hakimiyetini bildirmişlerdir. Çalışmamızda cinsiyete göre mantar karışımına $(p<0,05)$ ve hamam böceğine $(p<0,05)$ alerjen pozitifliği gösterilmiş ve gruplar arasında anlamlı fark olduğu tespit edilmiştir. Mülteci kadınların ortak çamaşırhane kullanması, çamaşır kurutma alan kısıtlılığı, çadır içinde serinlemek için sulu klima kullanılması ve erkeklere göre çadır içinde daha fazla zaman geçirmeleri mantar ve hamam böceği alerjen pozitifliğini açıklamaktadır. Uyruğa göre cinsiyet grupları arasında Suriyeli mülteci kadınlarda mantar karışımı $(\% 61,9)$ anlamlı düzeyde duyarlı olduğu saptandı.

Astımlılarda kadın cinsiyet ön plandadır. Bu durum bölge insanının tarımla uğraşması, tarımsal araziler ve yaşam alanları iç içe bulunması ile açıklanabilir. Yozgat'ta yapılan bir çalışmada tahıl (buğday) polen duyarlıığı \% 18,4 olarak bildirmiştir (22). Tarımsal arazilerin çok olduğu Şanlıurfa'da yapılan bir çalışmada tahıl (buğday) polen duyarlıı̆̆ $\% 53,3$ olarak bildirilmiştir (13). Çalışmamızda ise tahıl karışımına mültecilerde $\% 28,4$ ve T.C. vatandaşlarında $\% 40,2$ olmak üzere toplamda $\% 34,8$ oranda alerji pozitifliği ile bulunmuştur.

Bölgemizde yapılan bir çalışmada kedi, köpek gibi evcil hayvan sahipliği batıdaki gibi yaygın olmasa da alerji pozitifliği bildirilmiştir. Kedisi olmayan evlerin \%30'unda kedi alerjeni olduğu bildirilmiş̧ir (23). Koç ve arkadaşları kedi epiteline alerji pozitifliğini \%15,1 olarak bildirmiştir (13). Bizim çalışmamızda, çevrede sahipsiz sokak hayvanlarının olması nedeniyle kedi beslemeyenler de dahil, mültecilerde $\% 32$, T.C. vatandaşlarında $\% 38$ olmak üzere toplamda $\% 35,3$ oranında kedi epiteline alerji pozitifliği saptandı. Uyruğa göre T.C. vatandaşı kadınların kedi tüyüne $(\% 39,1)$ anlamlı düzeyde duyarlı olduğu saptandı.

Alerjenler sıklı̆ına, yaşanılan ve çalışlan coğrafik bölge, iklim türüne ve sosyoekonomik koşullara göre değişen sıklıkta alerjik hastalara etki edebilir. Çalışmamızda uyruğa göre gruplarda farklılık bulduk.

Sonuç olarak; Göç ve mültecilik durumlarında alerjik astım önemli bir sağlık sorunudur. T.C. vatandaşı ve mültecilerde en sık alerjen pozitifliği ev tozu akarında görülmektedir. Suriyeli mültecilerde sırayla ev tozu akarı, ot karışımı ve mantar karışımı şeklindedir. T.C. vatandaşı kadınların yabani ot ve kedi tüyü duyarııı̆ının, Suriyeli mülteci kadınların mantar karışımı ve Suriyeli mülteci erkeklerin yabani ot duyarlılı̆ının daha fazla olduğu saptandı. Bu çalışma T.C. vatandaşları ile Suriyeli mültecilerde alerjen varlığını karşılaştıran bir çalışma olmasıyla literatüre katkı sunacaktır.

Etik Onam: Bu çalışma için Harran Üniversitesi girişimsel olmayan etik kuruldan 06.04.2017 tarihli ve 17/04/23 no'lu kararı ile izin alınmıştır. 


\section{Kaynaklar}

1. Boulet LP, Reddel HK, Bacharier LB, Bateman ED, Becker A, Bruselle, et al. The revised 2019. Global Initiative for Asthma. Global Strategy for Asthma Management and Prevention, 2019.

2. Yıldız F, Oğuzülgen IK, Dursun $B$, Mungan $D$, Gemicioğlu $B$, Yorgancıoğlu $A$, et al. Turkish Thoracic Society asthma management and prevention guideline: key points. Tuber Toraks 2011;59(3):291-311 3. Arruda LK, Barbosa MC, Santos AB, Moreno AS, Chapman MD, Pomes A. Recombinant allergens for diagnosis of cockroach allergy. Curr Allergy Asthma Rep 2014;14:1-11.

4. Kalyoncu F, Çöplü L, Selçuk ZT, Emri AŞ, Kolaçan B, Kocabaş A, et al. Survey of the allergic status of patients with bronchial asthma in Turkey: a multicenter study. Allergy 1995;50:451-5.

5. Frati F, Incorvaia C, Cavaliere C, Di Cara G, Marcucci F, Esposito S, Masieri S. The skin prick test. J Biol Regul Homeost Agents 2018;32(1 Suppl. 1):19-24.

6. http://www.ceylanpinar.gov.tr/ Erişim Tarihi: 25 Aralık 2018.

7. Mowafi H. Conflict, displacement and health in the Middle East. Glob Public Health 2011;6:5 472-87.

8. Peltokorpi V. İntercultural communication in foregien, subsidiaries, the influence Expatriates language and cultural competencies. SJM 2010;26:2 176-88.

9. Çıtıl R, Eğri M. Migration and Infectious Diseases. Türkiye Klinikleri J Public Health-Special Topics 2017;3:1 14-21.

10. Ahmed H, Ospina MB, Sideri K, Vliagoftis $H$. Retrospective analysis of aeroallergen's sensitization patterns in Edmonton, Canada. Allergy Asthma Clin Immunol. 2019;13;15:6.

11. Farrokhi S, Gheybi MK, Movahed A, Tahmasebi R, Iranpour D, Fatemi $A$, et al. Common aeroallergens in patients with asthma and allergic rhinitis living in southwestern part of iran: based on skin prick test reactivity. Iran J Allergy Asthma Immunol 2014;14:133-8.

12. Bayram N, Uyar M, Elbek O, Dikensoy Ö, Ayeten F. Allergy skin test results of an outpatient pulmonary clinic in Gaziantep. Gaziantep Med J 2013;19:152-4.

13. Koç I, Doğan $Y$, Doğan $S$, Karataş ZA., Skin prick test results of atopic asthmatic subjects in a chest disease clinic in Sanliurfa, Dicle Medical Journal, 2015;42(2): 166-9

14. Oudin A, Richter JC, Taj T, Al-nahar L, Jakobson K. Poor housing conditions in association with child health in a disadvantaged immigrant population: a cross-sectional study in Rosengård, Malmö, Sweden. BMJ Open 2016;6:007979.

15. Radhakrishnan D, Guttmann A, To T, Reisman JJ, Knight BD, Moiaverian N, Manuel DG, et al. Generational Patterns of Asthma Incidence among Immigrants to Canada over Two Decades. A Population-based Cohort Study. Ann Am Thorac Soc. 2019;16(2):248-257.

16. El-Sharif N, Abdeen Z, Qasrawiz R, Moens G, Nemery B. Asthma prevalence in children living in villages, cities and refugee camps in $\mathrm{Pal}-$ estine. Eur Respir J 2002;19: 1026-1034

17. Kurtuluş Ş, Sak ZHA, Can R. Chest Diseases in Refugees Living in a Tent Camp and in Turkish Citizens Living in the District: Ceylanpınar Experience. Turk Thorac J. 2018;19(3):117-121.

18. Gupta A, Singh M, Chakrabarti A, Mathew JL, Rawat A. Correlation between fungal sensitisation in childhood persistent asthma and disease severity. Mycoses. 2018;61(3):195-200.

19. Jeong KY, Son M, Lee JH, Hong CS, Park JW. Allergenic characterization of a novel allergen, homologous to chymotrypsin, from german cockroach. Allergy Asthma Immunol Res 2015;7(3):283-9.

20. Mahesh $P$, Kummeling I, Amrutha $D$, Vedanthan $P$. Efect of area of residence on patterns of aeroallergen sensitization in atopic patients. Am J Rhinol Allergy. 2010;24(5):98-103.

21. Kalyoncu AF, Stalenheim G., Serum IgE levels and allergic spectra in immigrants to Sweden. Allergy. 1992;47:277-80.

22. Çölgeçen E, Özyurt K, İntepe YS, Gencer, ZK, Özkııış M, Ede G, Karaçavuş S. Skin prick test results in patients with atopic symptoms in Yozgat district. JCEI 2014;5: 64-8.
23. Custovic A, Taggart SC, Woodcock A. House dust mite and cat allergen in different indoor environments. Clin Exp Allergy 1994;24:11648. 